\title{
BÜCHNER, WOYZECK, ZÉ: POR QUE USAR O VERSO EM CENA?'
}

\author{
Fernando Marques
}

\section{Resumo}

$\mathrm{Na}$ primeira parte deste artigo, mencionamos as obras do escritor alemão Georg Büchner (1813-1837), considerando especialmente o drama Woyzeck. Ressaltamos a novidade temática e estética dessa peça, pioneira em apresentar um homem despossuído no papel principal, obra com a qual Büchner se converteria em precursor de naturalistas e expressionistas. Nas seções finais, abordamos as razões para compor a peça Zé, adaptação em verso e canções de Woyzeck. $O$ verso pode conferir ao texto certas qualidades musicais, as quais ampliam o campo de significações da peça teatral. Exemplos tomados a Zé são utilizados para expor tais hipóteses.

\section{Palavras-chave:}

Teatro Político; Teatro e Poesia; Ideias Estéticas.

\section{0 pé-rapado no papel principal convenções e ruptura}

Autor de repertório breve, mas seminal - composto por três peças teatrais, um panfleto político e uma novela -, o alemão Georg Büchner (18131837) teve a obra publicada na íntegra apenas em 1879, inspirando gerações de criadores desde então. Naturalistas e expressionistas viram no dramaturgo um precursor, tanto no plano dos temas, que ele tornou socialmente incisivos, quanto no plano das formas, alteradas para a expressão de novos conteúdos. Büchner nasceu há pouco mais de 200 anos, que se completaram a 17 de outubro de 2013.

Antes de chegar ao tema anunciado no título, que alude a Zé, adaptação em verso e canções do Woyzeck de Büchner, menciono a tradição teórica relativa à tragédia, na qual se destaca o filósofo alemão Friedrich Hegel (1770-1831). Revisitemos

\section{Abstract}

In the first part of this article we mention the works of the German writer Georg Büchner (18131837), especially considering the drama Woyzeck. We emphasize the aesthetic and thematic novelty of this play, a pioneer in presenting a dispossessed man in the lead role, work with which Büchner would become the precursor of naturalists and expressionists. In the final sections, we discuss the reasons for composing the play Zé, adaptation in song and verse of Woyzeck. The verse can give the text some musical qualities, which amplify the meanings of the play. Examples taken from Zé are used to expose such hypotheses.

\section{Keywords:}

Political Theater; Drama and Poetry; Aesthetic Ideas.

por um momento as ideias do influente Hegel, segundo comentadas pelo crítico literário inglês Raymond Williams (1921-1988) no ensaio Tragédia moderna. O objetivo é o de ressaltar a novidade do teatro büchneriano, como se verifica no drama Woyzeck. Entre outros aspectos pioneiros, a peça apresenta um homem pobre, despossuído, no papel central.

Williams fala sobre o filósofo em uma das seções de seu ensaio, explicando: "O importante na tragédia, para Hegel, não é o sofrimento enquanto tal - 'mero sofrimento' - mas as suas causas. Meros sentimentos de piedade e terror não são piedade e terror trágicos". Estes "remetem a um tipo específico de ação que é 'conforme à razão e à verdade do Espírito'" (WILLIAMS, 2002, p. 54).

O propósito de Williams consiste justamente em rastrear o modo como a teoria, dos gregos aos 
modernos, delimitou a área do que se entende por dignidade trágica, dela excluindo "ocasiões de contingência inteiramente externa e circunstancial, ocasiões para as quais o indivíduo não contribui, e pelas quais ele também não é responsável, como doenças, perdas de propriedade, morte e similares", afirma o filósofo alemão (HEGEL apud WILLIAMS, 2002, p. 54-55).

Deliberação, vontade, impressa pelo personagem nos atos por ele praticados, e consciência do efeito desses atos - vontade e consciência ligadas à relevância social do herói - são condições para que se dê a legítima tragédia, pensa o prestigioso Hegel. Histórias que não atendam a tais condições não serão consideradas trágicas.

Nessa ordem de ideias, a compaixão pelos desafortunados ou, antes, certo desdém por esse sentimento pauta-se em Hegel, conforme repara Raymond Williams, por uma "linguagem similar à das proposições de decoro". A noção de decoro havia definido o comportamento adequado a homens nobres, dando o tom ao código aristocrático da tragédia neoclássica (a de Racine, por exemplo), gênero de peças dirigidas às cortes e inevitavelmente marcadas por essa circunstância.

A conclusão, que nos pode parecer espantosa hoje, é de que a piedade não se destina ou mesmo não se deve destinar a qualquer pessoa que sofra, mas somente àquelas que a mereçam: "O homem de nobreza e grandeza (...) não tem nenhum desejo de ser sufocado por esse tipo de piedade" quanto aos desafortunados, assevera Hegel. "A verdadeira comiseração", sentimento associado às mais altas instâncias éticas, "não é, obviamente, estimulada por maltrapilhos e vagabundos." É o bom filósofo quem o afirma (HEGEL apud WILLIAMS, 2002, p. 55).

O aparente desprezo de Hegel, nesse âmbito, por todo sofrimento que não se eleve a planos efetivamente trágicos é digno de nota. $O$ ponto de discussão para nós reside, é claro, no que se considera efetivo ou legítimo em tais casos. ${ }^{2}$

As atitudes de desprezo pela sorte de personagens que não possuem as qualidades requeridas para o herói na tragédia - elevado papel social, autodeterminação, consciência -, em teatro e teoria teatral, correspondem, guardadas as proporções, às convicções políticas que levam entidades como a Subprefeitura da Mooca, em São Paulo, em episódio ocorrido em abril de 2013, a tratar moradores de rua como animais, expulsando-os dos locais onde dormem e tomando-Ihes documentos e objetos, inclusive instrumentos de trabalho. "Maltrapilhos e vagabundos" não têm inspirado piedade nem a filósofos nem a governantes. ${ }^{3}$

$O$ viés social que enfrenta, à base do que Brecht chamaria de "pensamento grosso", o elitismo solene de alguns dos mais importantes teóricos da literatura, elitismo alicerçado em alegações morais e técnicas, distingue a empresa realizada por Williams no que toca à teoria da tragédia e que podemos relacionar aqui ao Woyzeck de Büchner. A peça, de 1836 , seria publicada apenas em 1879 , tendo sido encenada somente a 8 de novembro de 1913 - há um século, portanto.

O escritor morreu aos 23 anos, deixando três peças - Woyzeck, A morte de Danton e Leonce e Lena - e uma novela intitulada Lenz, nome de um dos autores que surgiram com o movimento Sturm und Drang (Tempestade e Ímpeto), nos anos 1770. Redigiu ainda, com Friedrich Weidig, o panfleto 0 mensageiro de Hesse.

A tradição crítica não foi sempre elitista: soube perceber, no soldado raso Franz Woyzeck, um dos primeiros protagonistas proletários, senão o primeiro, da história da literatura dramática. Dito de outra forma, Woyzeck antecipa o naturalismo em várias décadas ao destinar a um despossuído o papel principal. Sim, os pobres, desde os gregos, frequentaram as comédias; mas nunca foram vistos nas tragédias em papéis centrais.

No gênero trágico, que Aristóteles e seus descendentes consideram o mais nobre, gente do povo só aparece em papéis auxiliares, secundários. Amas e confidentes surgem nas peças de Eurípedes e Racine; personagens populares habitam as peças de Shakespeare - basta lembrar os coveiros em Hamlet ou o porteiro bêbado em Macbeth. Mas a nenhum desses dramaturgos, nem mesmo a Shakespeare, rebelde às convenções clássicas, ocorreria dar a um borra-botas a função protagonista em uma tragédia - ou num drama, gênero que progressivamente substituiria a tragédia a partir do século XVIII, mantendo, porém, algumas das velhas convenções.

Büchner logrou a façanha, o que se explica por 
suas opiniões políticas, pela ocasião histórica em que escreve - cerca de quatro décadas depois da contraditória e mítica Revolução Francesa - e, do ponto de vista especificamente literário, em parte por sua admiração pelos renovadores do grupo Tempestade e Ímpeto (Goethe, Lenz, Schiller; os dois primeiros, sobretudo). Trazer para o centro da cena personagens associados à classe dos perdedores e anti-heróis correspondia a humanizá-los.

Eis o primeiro feito de Georg Büchner, capaz de chamar a atenção dos pósteros, entre eles os dramaturgos Hauptmann e Wedekind, na década de 1880; o músico Alban Berg, autor expressionista da ópera Wozzeck, de 1925; Bertolt Brecht ou, mais perto de nós, o cineasta Werner Herzog que, em parceria com o ator Klaus Kinski, levou à tela em 1979 o convulso, exasperado personagem. ${ }^{4}$

No Brasil, nossos encontros com Woyzeck se iniciam em 1948, quando Ziembinski encena a peça, em tradução de Mário da Silva. O próprio diretor interpretou o papel principal, com Maria Della Costa no de Maria, a namorada do soldado. O espetáculo cumpriu temporada de apenas 11 dias, no Rio de Janeiro, e se chamou Lua de sangue, colhendo para o título uma sugestão simultaneamente realista e metafórica: a imagem da lua que, indiferente e plena, assiste ao assassinato da moça pelo namorado, imagem superposta à do punhal. A lâmina ordinária, ensanguentada, mistura os tons vermelho e prata. ${ }^{5}$

A cena espelhava-se em crime que realmente ocorrera, na Alemanha de 1821, tendo sido o Woyzeck histórico enforcado em 1824. A defesa sustentara a inimputabilidade do assassino, destemperado ao extremo e incapaz de responder por seus atos. Sem dúvida, Büchner o retrata como homem desequilibrado e frágil, mas, a meu ver, não deixa de insinuar alguma consciência em Franz, não no momento mesmo do crime, quando age tomado por comoção, mas durante os preparativos, quando compra, aparentemente a frio, a lâmina barata com que vai matar Maria.

No entanto, ressalte-se, Büchner mostra o ato não como circunscrito a seu autor, mas dá grande relevo ao contexto, ao ambiente social, onde pululam as figuras entre caricatas e cruéis do Capitão e do Médico, que exploram e humilham Woyzeck. O Médico o transforma em cobaia de experiências pseu- docientíficas, submetendo-o a uma dieta exclusiva de ervilhas, cumprida pelo soldado em troca de moedas. O Capitão o exaspera com insinuações quanto à infidelidade de Maria. 0 ato extremo, sugere Büchner, resulta de uma soma de pressões pelas quais Franz afinal se deixa derrotar.

Esse relevo dado ao contexto cifra-se já na forma episódica, épica, adotada pelo autor. Recorro a palavras usadas na introdução à peça Zé, adaptação que fiz do Woyzeck, para indicar genericamente os traços épicos, opostos aos que definem o tradicional estilo dramático. Lá dizia que "o texto épico interessa-se não somente pela sorte dos indivíduos, mas procura enxergá-la na moldura de quadros e processos mais amplos, sociais, portanto. Os recursos mobilizados para a obtenção desses efeitos remetem à história apresentada aos saltos, em cenas relativamente independentes umas das outras, buscando-se o painel, o mosaico". ${ }^{6}$ Enfim, mostram-se processos, mais do que se delineiam personalidades, embora o perfil do miliciano maltratado pelos superiores, traído pela namorada e espancado pelo rival seja bastante incisivo também nos aspectos psicológicos.

Incidem ainda, no Woyzeck, os dados do acaso: o texto permaneceu inconcluso; Büchner não chegou a terminá-lo, tendo deixado quatro manuscritos nos quais as cenas têm redação e sequência distintas. Por tudo isso, parece convidar a releituras e adaptações.

\section{Mário de Andrade, Sigmund Freud: por que usar o verso em cena?}

Propusemos essa pergunta e tentamos responder a ela em artigo originalmente publicado em 2003.7 Por que usar o verso em cena? Parto do que diz Mário de Andrade em seu Ensaio sobre a música brasileira, no qual aponta as qualidades dinamogênicas da música, isto é, a sua capacidade de comunicar-se com os nossos ritmos orgânicos sem apelo primeiro à inteligência, mas endereçando-se, de maneira imediata, ao senso motor e aos sentidos.

Lembrando que em teatro o verso já foi regra, enquanto a prosa era exceção (veja-se Molière, por exemplo), constato a existência de diversos graus, relativos à regularidade rítmica, para a palavra 
falada ou cantada em cena. A escala começa na prosa e segue da prosa ao verso livre; do verso livre ao verso medido, metrificado, mas branco, ou seja, sem rimas; deste ao verso medido e rimado; por fim, no limite da escala, encontraríamos o verso que, já vizinho da música por apoiar-se em metro e rimas, fosse cantado, adicionando-se de ritmo definido e de alturas precisas.

Essas observações levam a uma primeira conclusão: se usarmos, em cena, o verso medido e rimado, estaremos próximos da música e da capacidade que essa arte possui de mobilizar o espectador em seus centros sensíveis, em seu inconsciente. Para não mencionar o próprio canto, é claro, com o qual a coincidência de teatro e música estaria completa. Essa conclusão preliminar liga-se às afinidades entre verso e música, supondo-se que o verso medido possua qualidades similares às da música - além de se associar a ela diretamente quando se converte em canção.

A esta altura, entram em cena Freud e o inconsciente, região psíquica mapeada por ele no livro A interpretação dos sonhos. ${ }^{8}$ A hipótese de que o verso possa mobilizar, pelo ritmo, a estrutura física do espectador conecta-se, agora, ao fato de que a sensibilidade ao ritmo, de um lado, e o pensamento por imagens, a imaginação metafórica, ligada aos sonhos, de outro, procedem ambos da mesma fonte: o inconsciente. Assim, torna-se legítimo afirmar que exista uma relação estreita, certa fraternidade entre o estímulo rítmico e o pensamento por imagens. Metáfora e ritmo se associam, são primos.

Seguindo em nosso raciocínio, constatamos: o teatro frequentemente se pauta pelo diálogo; e, toda vez que há diálogo, a moldura social se apresenta ou se insinua. Essa moldura, seja ela qual for, deve caracterizar-se, ao menos em certa medida, por uma lógica pedestre, ligada à vida rotineira, mesmo no mais alto dos dramas - pois toda conversa precisa manter-se no plano do inteligível.

No entanto, quando o diálogo teatral aparece em verso, aquela virtude dinamogênica, própria das canções, tende a afirmar-se. Com ela, "uma lógica menos rígida, pertinente à metáfora e a todo o arsenal da poesia lírica, invade, domina ou pode dominar a cena" (conforme o artigo de 2003). A palavra no palco, feita versos e som, poderá abarcar um campo semântico mais largo do que a prosa poderia abranger. Eis a resposta simples à pergunta "por que usar o verso em cena?": o texto em verso estimula a fantasia, convida a sonhar.

Os valores rítmicos que aproximam a poesia da música não se resumem, claro, a metro e rima. Envolvem também as estruturas estróficas, os paralelismos e os jogos semânticos (estes, característicos da poesia).

Esses valores "conjuram os poderes da imaginação, ao mesmo tempo que emprestam a eles forma definida", isto é, forma sensorial, corpórea. Metáfora e ritmo, a seu modo incisivo e singular, ajudam a compreender a realidade, inclusive a social ou objetiva. É de se acreditar que, sem as janelas abertas pelas lentes da poesia, a realidade "permaneceria opaca em alguns de seus aspectos essenciais, pouco permeáveis à pura visada lógica". 9

Acrescento: esses aspectos essenciais da realidade, os quais a poesia tem o poder de iluminar, parecem residir nas esquinas onde as instâncias social e pessoal, universal e local, abstrata e corpórea se misturam de maneira a não mais se deixarem distinguir. A inteligência divide para perceber, separa elementos com vistas a compreendê-los meIhor (na esperança de reuni-los depois), enquanto a imaginação metafórica, associada ao estímulo rítmico, opera por síntese, relacionando as coisas por afinidade e contraste, um pouco à maneira dos sonhos. São duas formas básicas de apreender o mundo, a analítica e a poética; desnecessário dizer que precisamos de ambas.

Menciono a seguir trechos da peça Zé, ilustrando o trabalho que busquei fazer ao adaptar Woyzeck em verso e canções.

\section{Poesia e estrutura dramática}

Vali-me de diversos metros em Zé - pareceu-me não haver por que insistir em uma só medida. Assim, utilizo o verso de cinco, seis, sete, oito, nove ou dez sílabas. O verso de sete sílabas, comum em português tanto na poesia popular quanto na poesia culta, aparece com frequência na peça. É uma espécie de coringa a que se recorre quando se quer garantir fluência e leveza.

O metro de nove sílabas, não tão comum, surge 
em momentos específicos, que se pretendem relacionados uns aos outros. Já o decassílabo sugere certa solenidade e às vezes comparece parodicamente ao texto. Os metros casam-se ao número de versos por estrofe e à distribuição das rimas, conforme cada trecho.

Na primeira cena, o metro é o de cinco sílabas, medida breve e, portanto, ágil. As estrofes têm cinco versos cada, com o seguinte esquema de rimas: o primeiro verso casa-se com o último, o segundo com o terceiro, enquanto o quarto fica solto. 0 motivo de ligar o primeiro verso ao quinto foi o de tentar tornar menos óbvio o efeito da rima. Capitão e Zé dialogam, enquanto o soldado barbeia o oficial. A autoridade o repreende:

\section{Capitão $^{10}$}

- Calma, José, calma!

Assim fico tonto.

O bigode pronto

em tempo tão curto

não vale uma palma!

Calma, homem, calma!

Ganhei dez minutos

exatos, enxutos.

Pra que tanta pressa?

Mais vale é a alma...

Adiante, o Capitão, sempre a depreciar o miliciano, condena-o por ser pai sem ser casado, ao que Zé vai responder dando mostra de que entende o próprio e precário papel social:

\section{Zé}

- Nós, pés de chinelo...

Sabe, o dinheiro,

quem não tem dinheiro...

Temos carne e sangue, mas sangue amarelo.

Somos desgraçados

neste e noutro mundo.

Lá no céu profundo,

mesmo lá, seremos

somente empregados.

Outro caso liga-se ao metro de nove sílabas, com o qual se fazem os versos da "Canção de Maria". A música aparece em versão instrumental já na abertura e, com letra, na terceira cena da peça. Embora escrita em forma de diálogo, é cantada em solo por Maria, como se pensasse em voz alta:

\section{Maria (cantando)}

- Maria, teu homem foi embora.

Com cria de colo e tão sozinha,

menina, que vais fazer agora?

Cantar e dançar a noite toda,

perdi o meu homem mas, sozinha,

mil outros então à minha roda estão

Com quais artifícios alimentas

a cria que levas em teu braço,

Maria, e como te sustentas?

Aprendo a dançar na noite acesa,

nas ruas escuras onde caço

fregueses às vezes, a tristeza, não

O eneassílabo é replicado noutros momentos. Por exemplo, quando Maria, em casa com seu filho (cena 8), lembra-se do Tamboreiro-mor, que ela viu passar e por quem se encantou. A moça traz um par de brincos nas mãos, presente do militar 
que a corteja. Pensando ao mesmo tempo em Zé e no Tamboreiro, diz para si própria, mesclando as reflexões a ordens dirigidas à criança, que permanece acordada:

\section{Maria}

- Um homem mandou o outro embora!

(Olha-se no pedaço de espelho.)

As pedras que brilham... Pedras lindas...

Falou que elas eram... (ao Menino) Mas agora

de olhos fechados, que o papão...

(A criança esconde os olhos com as mãos.)

Agora! Fechados, mais ainda!

E fique quietinho, pois senão...

(Cantarola murmurando, boca fechada,

a "Canção de Maria".)

Sublinho: os versos dessa fala têm o mesmo metro dos versos da canção, o que confere caráter temático ao embalo das nove sílabas; com ele é reiterado o motivo dessa passagem na qual se enfatizam os sentimentos de Maria. A seguir, mudase o metro de nove para sete sílabas e se somam novos dados à circunstância:

\section{Maria}

- É ouro, mas com certeza.

Será que me fica bem

no baile? Será que não?

Gente como eu, sem vintém,

que mal vale o quanto pesa,

o espelho achado no chão...

Mas tenho os lábios vermelhos

feito os das grandes madames

com seus homens tão bonitos,

faniquitos e vexames.
A alegria dos espelhos...

Mundo engraçado, esquisito.

Por fim, menciono exemplos relativos ao heptassílabo na canção "A profissão de Cátia", na cena 23, passada na taberna, e ao decassílabo do soneto dito pelo Policial, frente ao corpo de Maria, na penúltima cena da peça.

Cátia revela-se lúcida. Cantando em diálogo com Zé, afirma:

\section{Cátia}

- Eu não quero ser escrava

na copa de algum doutor, onde a louça que se lava

não me paga meu suor, onde a cova que se cava não vale o viver de amor! Por moedas não me dava, mas dando me dou melhor. Por moedas não me dava, mas dando me dou melhor.

- Eu não quero ser a moça

da roça de algum senhor, onde a lavra não é nossa

e é pobre a própria dor, onde a terra e onde a choça pertencem a seu major! Poderia estar na roça, mas dando me dou melhor.

Eu larguei a vida insossa, que dando me dou melhor! 
Já no desfecho (cena 26, penúltima), o funcionário analisa o crime:

\section{Policial}

- Se não me engano, crime passional:

tantas facadas pedem um Otelo.

Um bom assassinato, nada mal.

Um verdadeiro assassinato, e belo.

De fato, os vários golpes de punhal,

dados à pressa e sem sinal de zelo,

demonstram que não é profissional

o doido que entendeu de cometê-lo.

Um crime de amador, literalmente,

nos dois sentidos que a palavra tem:

a lâmina ordinária, sem mestria,

dilacerou a carne de Maria.

Mas quem não ama não mata assim tão bem...

Havemos de pegar o delinquente.

Deixo ao leitor a sugestão de que visite o texto, quem sabe procurando verificar o efeito temático de certas recorrências sonoras e semânticas, pelas quais o verso exerce o seu papel na estrutura geral das cenas.

Falando em tese, em relação à qual a peça Zé será um caso particular, reitero: a imagem e o ritmo, intensificando-se mutuamente e tendendo juntos ao que chamei de forma corpórea, ajudam a compreender a realidade, inclusive a objetiva ou política; nem se poderia considerá-los de outro modo, como simples adornos. O real pareceria opaco, obscuro, informe se não dispuséssemos das lentes da analogia.

\section{Notas}

1. Trabalho desenvolvido a partir de dois textos do autor: "Büchner, Woyzeck, Zé", introdução à peça Zé, de 2003, e "A palavra no palco - por que usar o verso em cena", artigo publicado na revista Folhetim, no mesmo ano. Palestra pronunciada durante o VI Fórum Bienal de Pesquisa em Artes (UFPA, Belém); durante o simpósio Georg Büchner (18131837): 200 Anos (USP/Goethe-Institut, São Paulo); em participação no Festival IdA 25 anos (Instituto de Artes da UnB); e na Semana Gita - Grupo de Investigação do Treinamento Psicofísico do Atuante (UFPA, Belém), em 2013 e 2014.

2. Ignorar a dor anônima, comum, nas tentativas de explicar o mundo equivaleria a renunciar a entendê-lo - é o que se pode suspeitar. Em A morte de Danton, o inglês Payne, no contexto de uma discussão sobre a existência de Deus, ocorrida numa cadeia em Paris, durante a Revolução Francesa, afirma ideias afins: "Toma nota desta pergunta, Anaxágoras: por que sofro? É essa a cidadela do ateísmo. A mais leve contração de dor, ainda que se produza apenas num átomo, abre na criação uma fenda de alto a baixo". Georg Büchner, A morte de Danton, 1988, p. 72.

3. Segundo matéria da Agência Estado reproduzida em UOL Notícias (11-04-2013), "as autoridades declararam 'tolerância zero' a crime, lixo e moradores de rua". Já no Rio de Janeiro, um ano mais tarde, a polícia militar obedeceria com truculência à ordem judicial de reintegração de posse de terreno e prédio da empresa Oi, no Engenho Novo. Moradora da área disse ao portal Terra que os policiais praticaram "um verdadeiro massacre lá dentro" e que as famílias foram "enfileiradas como se fossem presidiários" (11-04-2014).

4. Vale citar ainda o DVD com a ópera Wozzeck, de Berg, dirigida por Sebastian Weigle (música) e Calixto Bieito (cena), produção catalã de 2006. Há também DVD com a ópera transformada em filme para a tevê, dirigido por Joachim Hess em 1970 (disponível no YouTube).

5. 0 encenador Ruggero Jacobbi havia sugerido a Sandro Polloni, produtor e ator do Teatro Popular de Arte, a montagem da peça alemã e depôs em 1956: "O espetáculo foi excelente. Ziembinski resolveu o problema das mudanças de cenário com habilidade e simplicidade. Alguns atores (Maria, 
Samborsky, Guerreiro) estavam extraordinários. Mas o texto, em sua aspereza, em sua falta de estrutura aparente, em sua pureza sem concessões, ficou inatingível, obscuro, para o grande público. Muita crítica demonstrou a incompreensão mais absoluta. Somente Pompeu de Souza escreveu uma 'louvação', que é uma de suas páginas mais vivas. Isto foi em setembro de 1948. Estamos ficando velhos; Woyzeck continua jovem, continua a ser 'um caso aberto'". Jacobbi, em: Yan Michalski, Ziembinski e o teatro brasileiro, 1995, p. 136-137.

6. Marques, São Paulo, É Realizações, 2013, p. 17.

7. O artigo, referido em nota anterior, chama-se "A palavra no palco - por que usar o verso em cena", publicado pela primeira vez na revista FoIhetim, n. 16, e republicado em Últimos - comédia musical, em 2008. Ampliado, saiu ainda na coletânea de artigos Poesia: o lugar do contemporâneo, de 2009, organizada por Sylvia Cyntrão. Neste segundo caso, procuro ilustrar o tema com exemplos tomados a peças teatrais.

8. Vali-me aqui de "A relação dos chistes com os sonhos e com o inconsciente", seção do livro Os chistes e sua relação com o inconsciente na qual Freud, em 1905, resume as ideias expostas cinco anos antes em $A$ interpretação dos sonhos.

9. Segundo artigo de 2009, citado.

10. As citações de Zé procedem da segunda edição da peça (São Paulo, É Realizações, 2013). Aponto apenas as cenas de que os trechos foram extraídos, dispensando a menção das páginas.

\section{Referências}

ANDRADE, Máriode.Ensaio sobreamúsicabrasileira. 3a. edição. São Paulo: Martins; Brasília:INL, 1972. ARON, Irene. Georg Büchner e a modernidade. São Paulo: Annablume, 1993.

BÜCHNER, Georg. A morte de Danton. Tradução: Mário da Silva. Rio de Janeiro: Ediouro, 1988.

A morte de Danton. Tradução: Maria Adélia Silva Melo e Jorge Silva Melo. Lisboa: Teatro Nacional D. Maria II/Bicho do Mato, 2012.

Woyzeck e Leonce e Lena. Tradução: João Marschner. Rio de Janeiro: Ediouro, 1989.
. Woyzeck. Tradução, apresentação e notas: Tércio Redondo. São Paulo: Hedra, 2003.

O mensageiro de Hesse. Em: Cadernos de Teatro Alemão, n. 37. Tradução: Felicia B. Volkart. Porto Alegre: Institutos Goethe do Brasil, 1982.

. Lenz. Em: Cadernos de Teatro Alemão, n. 37. Grupo de tradutores coordenado por A. Rudolph. Porto Alegre: Institutos Goethe do Brasil, 1982.

. Lenz. Em: BÜCHNER, Georg; SCHNEIDER, Peter. Lenz. Tradução: Irene Aron. São Paulo: Brasiliense, 1985.

CANETTI, Elias. "Georg Büchner". Em: A consciência das palavras. São Paulo: Companhia das Letras, 1990.

FREUD, Sigmund. "A relação dos chistes com os sonhos e com o inconsciente". Em: Os chistes e sua relação com o inconsciente. Tradução sob a direção geral de Jayme Salomão. Rio de Janeiro: Imago, 1977.

GUINSBURG, J.; KOUDELA, Ingrid D. (orgs.). Büchner na pena e na cena. Com as obras O mensageiro de Essen, A morte de Danton, Lenz, Leonce e Lena, Woyzeck e cartas. Tradução: J. Guinsburg e Ingrid D. Koudela. São Paulo: Perspectiva, 2004.

LENZ, J.M. Reinhold. Notas sobre o teatro. Em: LENZ, J.M. Reinhold. Notas sobre o teatro; GOETHE, J.W. Regras para atores. Tradução e prefácio: Fátima Saadi. Coleção Dramaturgias. Rio de Janeiro: 7Letras, 2006.

LOCKETT, Joseph L. "As good a murder as you'd ever want to see". Texto disponível na internet.

MAGALDI, Sábato. “Woyzeck, Büchner e a condição humana". Em: O texto no teatro. São Paulo: Perspectiva, 1989.

MARQUES, Fernando. Zé - peça em um ato. Adaptação do Woyzeck em verso e canções. Com a introdução "Büchner, Woyzeck, Zé". São Paulo: Perspectiva, 2003.

. Zé - peça em um ato. $2^{a}$. edição. Prefácio: Valmir Santos. São Paulo: É Realizações, 2013. . Últimos - comédia musical em dois atos. Livro-CD. Prefácio: Ilka Marinho Zanotto. São Pau- 
lo: Perspectiva, 2008.

Com os séculos nos olhos: teatro musical e político no Brasil dos anos 1960 e 1970 . São Paulo: Perspectiva, 2014.

"A palavra no palco - por que usar o verso em cena". Em: Folhetim, n. 16. Rio de Janeiro: Teatro do Pequeno Gesto, janeiro-abril de 2003.

"A palavra no palco - por que usar o verso em cena?". Versão ampliada do artigo de 2003. Em: CYNTRÃO, Sylvia Helena (org.). Poesia: o lugar do contemporâneo. Brasília: UnB/Departamento de Teoria Literária e Literaturas, 2009.

MICHALSKI, Yan. Ziembinski e o teatro brasileiro. Edição final: Fernando Peixoto. Colaboração: Johana Albuquerque. São Paulo-Rio de Janeiro: Hucitec; Ministério da Cultura/Funarte, 1995.

PEIXOTO, Fernando. Georg Büchner - a dramaturgia do terror. São Paulo: Brasiliense, 1983.

ROSENFELD, Anatol. "Büchner". Em: Teatro moderno. 2a. edição. São Paulo: Perspectiva, 1985.

THEODOR, Erwin. "Büchner, homem e autor". Em: Cadernos de Teatro, n. 93. Rio de Janeiro: 0 Tablado, abril-junho de 1982.

WILLIAMS, Raymond. Tragédia moderna. Tradução: Betina Bischof. São Paulo: Cosac e Naif, 2002.

\section{Ópera e filmes}

BERG, Alban. Wozzeck. CD. Direção de Ingo Metzmacher. Bo Skovhus (Wozzeck), Angela Denoke (Marie) e elenco. Com a Orquestra Filarmônica e o Coro da Ópera de Hamburgo. Gravação ao vivo, 1998. EMI, 1999.

BERG. Wozzeck. DVD com a ópera de Alban Berg, dirigida por Sebastian Weigle (música) e Calixto Bieito (cena). Franz Hawlata (Wozzeck), Angela Denoke (Marie) e elenco. Com a Orquestra Sinfônica e o Coro do Gran Teatre del Liceu, Barcelona. Gravação ao vivo, 2006. Opus Arte, 2007.

BERG. Wozzeck. DVD. Versão da ópera em filme para a televisão, dirigido por Joachim Hess. Regência: Bruno Maderna. Com a Orquestra Filarmônica e o Coro da Ópera de Hamburgo. Alemanha, 1970. Arthaus Musik. Disponível no YouTube.
HERZOG, Werner. Woyzeck. Filme dirigido por W. Herzog. Com Klaus Kinski. Alemanha, 1979.

WAJDA, Andrzej. Danton. Filme dirigido por A. Wajda. Com Gérard Depardieu. França/Polônia/ Alemanha Ocidental, 1983.

\section{Sobre 0 autor}

Fernando Marques é professor do Departamento de Artes Cênicas da Universidade de Brasília, escritor e compositor. Doutor em Literatura Brasileira pela UnB com tese sobre teatro musical. Publicou os livros Retratos de mulher (poemas; Varanda, 2001); Contos canhotos (LGE, 2010); Zé peça em um ato (2a. edição, É Realizações, 2013); Últimos - comédia musical em dois atos (livro-CD; Perspectiva, 2008); A comicidade da desilusão: - humor nas tragédias cariocas de Nelson Rodrigues (Editora UnB/Ler Editora, 2012) e Com os séculos nos olhos: teatro musical e político no Brasil dos anos 1960 e 1970 (Perspectiva, 2014). 